\title{
The acceptability of risks from natural disasters
}

\author{
D. J. Higson \\ Retired, Sydney, Australia
}

\begin{abstract}
Engineers may need to design structures for loads imposed by natural occurrences such as earthquakes and meteorological events of various kinds. No matter what event is specified as a design base, something worse is always physically possible. Hence, engineering standards imply a risk of failure due to large but unlikely external natural events. This risk is accepted. Little account is taken of earthquakes, tsunamis, tornadoes and hurricanes in areas that are judged not prone to them but anything that is physically possible has a finite probability of occurring. Tsunamis are possible on any exposed coastline; earthquakes and storms can occur anywhere. The probabilities of such events vary enormously but are rarely zero.

The acceptance of a risk by society depends more strongly on the nature of the risk than its size. This was clearly demonstrated by the disaster at Fukushima in March 2011. The earthquakes and tsunamis killed more than 15,000 people; radiation from the damaged Fukushima Daiichi nuclear power station killed no-one and is unlikely to have any public health effects; but fear of radiation has dominated public, media and political reactions to the disaster worldwide. In Japan, some risks to coastal communities from tsunamis are still accepted but the risk from nuclear power is considered by many to be unacceptable. Other nations, where tsunamis (the sole cause of damage to the nuclear plant) are not a matter of wide concern, have nevertheless turned away from the use of nuclear power. This means burning more fossil fuels, with greater industrial risks, environmental damage and harm to public health.
\end{abstract}

Keywords: risk, natural disaster, earthquake, tsunami, flooding, storm, meteorite, Fukushima, radiation. 


\section{Introduction}

Engineers may need to design structures for loads imposed by natural occurrences such as earthquakes and meteorological events of various kinds. A common way of doing this, giving a misleading sense of certainty, is to determine the worst event considered credible and design accordingly. If something worse then occurs and the structure fails, the best defence that designers can have is that they complied with the practice of their peers, viz: the standard. Such an event has sometimes been called an "Act of God".

One of the most famous "Acts of God" in history was the destruction of the city of Sodom during the third millennium BC. Harris [1] has studied the geological and historical evidence regarding this event and concluded that the destruction of Sodom was the consequence of an earthquake and tsunami. We know that earthquakes and tsunamis do occur with disastrous consequences well in excess of anticipated levels.

An alternative approach to design is to accept that anything that is physically possible has a finite probability of occurring, and to place a design limit on the risk that this will happen. Unfortunately, this opens the possibility (after the event) that a newspaper journalist could write - or a lawyer could stand up in court and say - "they knew it was going to happen".

\section{Some existing risk criteria}

In the design of large dams, the division between "credible" and "incredible" for natural events is $10^{-5}$ per year (once in a hundred thousand years but it could be this year). At least, that was the situation some years ago, when I last had any contact with the subject of dams. An earlier design base had been events with a probability of $10^{-4}$ per year (e.g. the "ten thousand year flood") but the risk of failure on this basis came to be considered too high.

A risk limit of $10^{-6}$ per year has been quoted for nuclear plant design. For seismic design, however, criteria are generally deterministic, not probabilistic, and are divided into two levels as follows:

- What was once called the "maximum credible earthquake" is now the $\mathrm{S} 2$ or "safe shutdown earthquake" (SSE), which is specified in terms of earthquake intensity at the site. This S2 or SSE is the design base for equipment that is essential for safety.

- The S1 or "operating base earthquake" (OBE) is a smaller (and therefore more likely) earthquake, which is the design base for equipment that is important operationally but is not essential for safe shutdown of the plant.

Thus, failure of equipment that has only operational significance is recognised as being a more acceptable risk than failure of equipment that has safety significance.

In civil engineering, it would not be practical - and would certainly not be justified economically - to design every building to survive (say) a Magnitude 7 earthquake beneath its foundations, even though that could conceivably happen; 
its probability being around $10^{-2}$ per year in some parts of San Francisco and less than $10^{-7}$ per year in many other parts of the world, but never zero. As Charles Bubb (Chairman of the Australian National Committee on Earthquake Engineering, 1971-1976) put it: "Every building will be destroyed by an earthquake eventually, unless something else destroys it first."

\section{Acceptable to whom?}

No matter what natural event is specified as a design base, something worse is always physically possible. Hence, the basis of design generally incorporates a risk of failure due to large but unlikely external natural events. How big a risk is acceptable? And is it possible to estimate the probability of such rare events reliably?

But first: The question to be asked is "acceptable to whom?" To individuals, groups or communities who are exposed to the risk, to authorities who are responsible for public safety or to some remote bureaucracy?

For individuals, the acceptable level of risk depends strongly on the nature of the risk. Average risks of death due to external natural events in Australia are small, viz:

- $10^{-9}$ per person-year from a meteorite strike (Higson [2])

- less than $10^{-7}$ per person-year from earthquakes and tsunamis

- $10^{-7}$ per person-year from being struck by lightning (Higson [2])

- $2 \times 10^{-7}$ per person-year due to storms and floods (Higson [2])

These risks are all accepted. The risk from meteorites is essentially unavoidable but the others are, to some extent, subject to personal choices. For example, many people choose to live in places where there are risks of tsunamis or floods.

I have actually not found any record of deaths attributed to a tsunami in Australia or to a meteorite anywhere in the world, but both are physically possible. Significant tsunamis have struck the coast of Australia without causing fatalities and I understand that there is geological evidence of much larger ones in the distant past, although perhaps not within the time of human habitation.

In 1989, I estimated the risk from a meteorite strike from reports of the frequencies with which meteorites of various sizes reach the earth's surface and estimates (made by others) of the consequences of a large strike. By far the majority of this risk is due to the possibility that a city could be destroyed by a large meteorite, causing many deaths. This is almost certainly unavoidable. Astronomers might see it coming but there is essentially nothing that could be done to divert or protect against it. A near miss actually occurred on 15 February 2013 when an asteroid, estimated to have a diameter of about 17 to 20 metres and a mass of about 10,000 tonnes, entered the earth's atmosphere over Russia. This caused a meteorite of mass $654 \mathrm{~kg}$ (later recovered) to fall into Lake Chebarkul. If it had struck the nearby city of Chelyabinsk, the entire population of over a million might have perished.

It is instructive to compare risks from natural causes with more familiar risks from "unnatural" causes such as: 
- $8 \times 10^{-5}$ per person-year from road traffic accidents (Higson [3])

- 1.8 x 10-3 per person-year from cancer (all causes) (Higson [3])

- 5 x 10-3 per person-year from smoking 20 cigarettes per day (Higson [2])

These risks are definitely subject to personal choices and are largely accepted by those exposed to them, although the authorities and/or relevant professional and lobby groups continually try to reduce them. Risks from road traffic accidents have decreased over the past 40 years, partly because of improved engineering of roads and cars. But two of the most effective reasons for reduction of the road toll - the mandatory use of seat belts (1974/6 in Australia) and random breath testing (1982 in NSW) - were opposed by many motorists when they were first introduced.

\section{Lessons learnt from major disasters that have occurred}

The main concern about the effects of natural disasters is when they might lead to many casualties and major damage from one event. Australia has been fortunate in not experiencing catastrophes on the scale that have struck some other parts of the world, for example:

- The volcanic eruption at Krakatoa, Indonesia, in 1883 and the resulting tsunami;

- Tsunamis on 26 December 2004 and 11 March 2011 caused by Magnitude 9 earthquakes off the coasts of Indonesia and Japan (Fukushima) respectively;

- The series of destructive earthquakes that struck Christchurch, New Zealand, commencing at Magnitude 7.1 on 4 September 2010 and continuing into 2012.

- $\quad$ Typhoon Haiyan, which struck the Philippines on 8 November 2013.

Nevertheless, natural disasters do occur in Australia. Two of the worst on record were:

- Cyclone Tracey, which caused 71 deaths in Darwin, Northern Territory, in 1974: Before the devastation caused by Cyclone Tracey, building standards in Darwin were generally considered acceptable by most stake-holders, even though the city had been severely damaged by cyclones several times during its history. After Tracey, standards were upgraded to the extent that some people considered the additional cost to be excessive.

- The Magnitude 5.6 earthquake which struck Newcastle, New South Wales, in 1989 causing 13 deaths, more than 160 injuries and extensive damage: This has been the only seismic disaster on such a scale in the history of Australia, which is often thought of as a relatively inactive continent seismically. Australia does in fact experience many earthquakes but, being vast and sparsely populated, its centres of population have rarely been affected. Several earthquakes of magnitudes around 7 have been recorded but never in the vicinity of a 
city. Building standards that were considered adequate before the Newcastle earthquake have since been upgraded.

One of the most important lessons to be learnt from natural disasters that have occurred is yet again that the acceptability of a risk depends more strongly on the source of the risk than the size of the risk. This has been illustrated clearly by the Fukushima disaster in March 2011.

The earthquakes and tsunamis left 25,000 dead, injured or missing at Fukushima. Flooding by the tsunami caused major damage to the Fukushima Daiichi nuclear power station. The ensuing evacuation, and other emergency measures taken to protect the public from exposure to radiation, disrupted more than 150,000 lives and caused more than 1000 deaths, including elderly people who were taken from their homes, hospitals and nursing homes and moved into far less adequate care. These disruptions, together with exaggerated fears of radiation, also caused many suicides.

In contrast, the UN Scientific Committee on the Effects of Atomic Radiation (UNSCEAR) [4] and the International Commission on Radiological Protection (ICRP) [5] report that no health effects have been observed that can be attributed to radiation exposure, either among workers or the general public. No member of the public was exposed to radiation at a rate outside the range of variation of natural background radiation around the world - and there is no direct evidence that natural radiation is harming anyone anywhere (except in some cases of $\alpha$-radiation from elevated radon levels in enclosed spaces, which has no relevance to reactor accidents). A risk from such low levels of radiation exposure can be estimated using the linear no-threshold (LNT) model recommended by the ICRP [6]. However, UNSCEAR [4] has recently withdrawn support for this application of LNT. The true value of this risk is more likely to be zero.

Nevertheless, far greater concern has been expressed about the nuclear accident at Fukushima than about the other aspects of the catastrophe. In Australia, the news media have concentrated their attention almost entirely on the former and largely ignored the latter, except in the immediate aftermath of the disaster.

In North-Eastern Japan, risks from earthquakes and tsunamis were accepted before 11 March 2011 - people lived, worked and invested their money in coastal areas. Some risks to housing of the general population from tsunamis will presumably have to be accepted in the future, because it is difficult to see how the risk could be eliminated in practice except by moving all residential areas to much higher ground. Apparently, in fact, the intention is to rebuild the urban areas and most of the industries that were destroyed.

On the other hand, Japan plans to reduce its dependence on nuclear power and there have been calls for it to be shut down altogether - even though the risk of flooding of emergency power supplies (which was the sole cause of the nuclear accident) can be substantially reduced in existing nuclear plants and essentially eliminated in new designs.

The risk from nuclear power is now considered to be unacceptable by many who previously accepted it. Some countries where tsunami risk is not normally an issue, such as Germany and Switzerland, have reacted by backing away from 
the use of nuclear power. The implications of such policies for alternative power supplies may themselves prove to be unacceptable. Apart from the economic implications, it will mean burning more fossil fuels, with increased industrial risks, environmental damage and harm to public health.

\section{Tsunami risk around the world}

The risk of a tsunami is less around the coasts of Europe and Australia than it is around the coast of Japan but it is not zero. Apart from seismic considerations, tsunamis can be caused by large meteorites, which have a random probability of striking any point on the earth's surface. This probability is extremely small at any particular point but, with three quarters of the earth's surface covered by water, the probability of a large meteorite landing in the ocean is not negligible. To cause a significant tsunami, the meteorite would have to be a fairly big one, perhaps of the size that reaches the earth's surface every thousand to a million years on average (between $10^{-3}$ and $10^{-6}$ per year), depending where it splashed down; the larger the meteorite the lower the probability. But remember: it is the same probability every year.

The meteorite would not have to be of the size that is said to have killed off the dinosaurs. Our only real protection against such an event is its low probability of occurrence.

\section{Conclusions}

Current engineering standards relating to earthquakes, tsunamis, floods and storms imply acceptable risks of failure. It is to be expected that the relevant standard would be raised if (or when) a design base event is exceeded and that this would reduce the acceptable risk.

The risk from tsunamis needs to be assessed, not only for nuclear power stations and other industries but also for coastal towns and cities anywhere in the world. It is unlikely that many people in Australia, Britain or elsewhere in Europe will want to think about this unless it is in the context of nuclear power.

\section{References}

[1] Harris, G., "The Destruction of Sodom: A Scientific Commentary". Lutterworth Press, Cambridge (Forthcoming title 2014). This study was the subject of a short article in the IMPERIAL ENGINEER (the engineering magazine of Imperial College, London) Spring 2012, p. 26.

[2] Higson, D.J., Risks to Individuals in NSW and in Australia as a Whole. Australian Nuclear Science and Technology Organisation: Nuclear Safety Bureau Report NSB2/1989, July 1989. (Some of the figures presented in this report were cited in the OPAL reactor safety case as the basis for comparative risk assessments used by the New South Wales Department of Planning.) 
[3] Higson, D.J., risks from reference [2], updated in accordance with Australian Bureau of Statistics (ABS), Yearbook Australia, 2007 and Causes of Death, Australia, 2008. (Risks are recorded as the number of deaths each calendar year per 100,000 of the population. Eight deaths per 100,000 per year is a risk of $8 \times 10^{-5}$ per person-year.)

[4] UNSCEAR's fifty-ninth session (21-25 May 2012). Supplement No. 46 in the Report of the United Nations Scientific Committee on the Effects of Atomic Radiation to the sixty-seventh session of the United Nations General Assembly, www.unscear.org.

[5] International Commission on Radiological Protection, Report of ICRP Task Group 84 on Initial Lessons Learned from the Nuclear Power Plant Accident in Japan vis-à-vis the ICRP System of Radiological Protection, 22 November 2012， www.icrp.org/docs/ICRP\%20TG84\%20Summary\%20 Report.pdf.

[6] International Commission on Radiological Protection, The 2007 Recommendations Of the International Commission on Radiological Protection, ed. J. Valentin. Annals of the ICRP: Publication 103, Elsevier, 2007. 